\title{
Physical Distancing and Self-Quarantine: An Exploration of International Postgraduate Students' Experiences During the Covid-19 Pandemic
}

\section{Abdallah Mpawenimana Saidi, Adam Andani Mohammed}

To Link this Article: http://dx.doi.org/10.6007/IJARBSS/v11-i3/8980

DOI:10.6007/IJARBSS/v11-i3/8980

Received: 01 January 2021, Revised: 31 January 2021, Accepted: 19 February 2021

Published Online: 16 March 2021

In-Text Citation: (Saidi \& Mohammed, 2021)

To Cite this Article: Saidi, A. M., \& Mohammed, A. A. (2021). Physical Distancing and Self-Quarantine: An Exploration of International Postgraduate Students' Experiences During the Covid-19 Pandemic. International Journal of Academic Research in Business and Social Sciences, 11(3), 722-732.

Copyright: @ 2021 The Author(s)

Published by Human Resource Management Academic Research Society (www.hrmars.com) This article is published under the Creative Commons Attribution (CC BY 4.0) license. Anyone may reproduce, distribute, translate and create derivative works of this article (for both commercial and non-commercial purposes), subject to full attribution to the original publication and authors. The full terms of this license may be seen at: http://creativecommons.org/licences/by/4.0/legalcode

Vol. 11, No. 3, 2021, Pg. 722 - 732

Full Terms \& Conditions of access and use can be found at http://hrmars.com/index.php/pages/detail/publication-ethics 


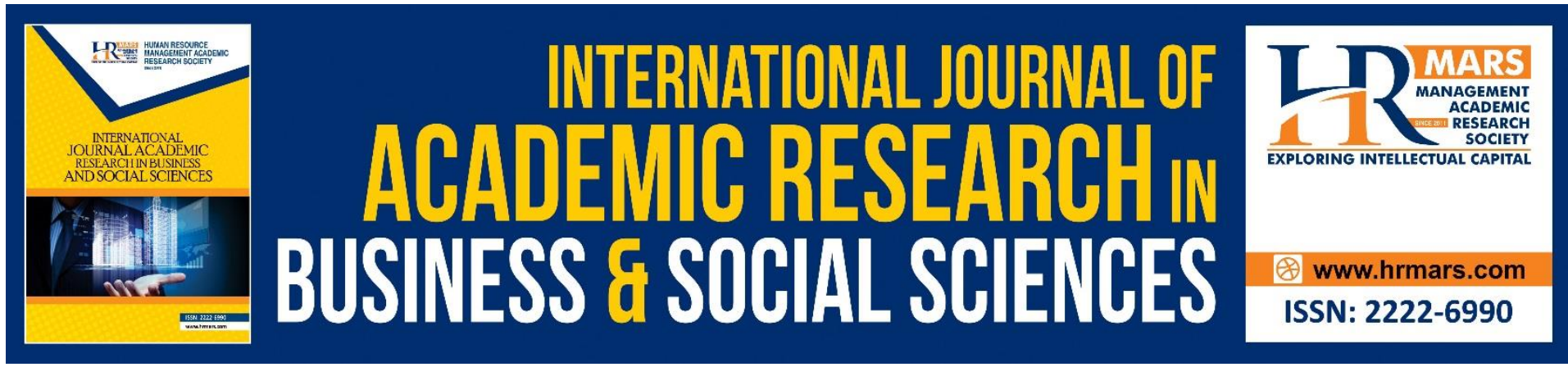

\title{
Physical Distancing and Self-Quarantine: An Exploration of International Postgraduate Students' Experiences During the Covid-19 Pandemic
}

\author{
Abdallah Mpawenimana Saidi \\ Department of International Studies, Faculty of Social Science and Humanities, Universiti \\ Malaysia Sarawak, Kota Samarahan Sarawak, Malaysia. \\ Email: asmpawenimana@unimas.my
}

\section{Adam Andani Mohammed}

Social Work Studies, Faculty of Social Sciences and Humanities, Universiti Malaysia Sarawak,

Kota Samarahan Sarawak, Malaysia.

Email: maandani@unimas.my

\begin{abstract}
The thought of infection with the fatal COVID-19 virus and physical distancing may make students develop mental stress, anxiety, loneliness and if possible depression. The physical distancing is considered an essential public health intervention that could curb the transmission of the coronavirus. This study adopted a qualitatively structured and open ended question using interview protocol. The questions were designed to find out the respondents' experience of COVID-19 and the effects of physical distancing and selfquarantine on them and the ways of adjustment to cope with the situation. Initially, calls on WhatsApp were made to ascertain the willingness of those selected to be part of the survey. An online interview protocol was sent to students at various locations in Kota Samarahan and Gombak. The protocol was administered through email and a period of 10 days (April $18-28$, 2020) was given for it to be returned. Half of the 30 protocols returned were postgraduate who served as respondent for the study. The study found that those who stay off campus could go to the supermarket for groceries but needs to observe the physical distancing.
\end{abstract}

Keywords: COVID-19, Physical Distancing, Postgraduate, Isolation, Quarantine, Infection.

\section{Introduction}

The World Health Organization got the information about the disease from China on 31st of December, 2019, and declared it a pandemic on March 11, 2020. It is revealed that there were 1,853,183 cases of COVID-19 causing 114,248 deaths worldwide as of April 13, 2020, 04:10 GMT (Ducharme, 2020; Egunjobi, 2020). Since there is no cure for COVID-19 and no vaccine yet everyone is required to self-quarantine or physical distance observance of which 
led to lockdowns in many cities and nations across the world (Mohammed, Uddin \& Saidi, 2020). As such, Joob (2020) suggested that public health information should be available in multiple languages if possible and diffused through various communication channels and networks as soon as possible for the general public, especially students. As the search for a vaccine continues, some of the essential ways to slow the spread of the pandemic include but not limited to self-quarantine and physical distancing which students are observing at their various location. However, these affect the instinct to connect with others and thus people, for that sense student, find it difficult regulating their emotions and coping with stress in observing self-quarantine (Mohammed, Uddin, \& Saidi, 2020). Van et al (2020) opined that the increase in negative feelings imply that the public concern much about negative information of COVID-19 more than other positive information. For instance, reading and watching reports of the number of people infected and numbers of death instead of those who have recovered from the infection. Van et al. (2020) however indicated that distancing threatens to aggravate feelings of loneliness and could produce negative long-term health consequences. According to UNESCO, almost 1.3 billion students have been affected by the novel coronavirus (Covid 19) around the world. Schools and universities have been trying to adjust to distance learning with very little notice and varying success. As such students have been left to grapple with the fact that no one knows for sure when or if things will get back to normal. Studies show that people subject to quarantine or self-isolation are at risk for confusion, anger and possibly frustrations (Brooks et al., 2020; Van et al., 2020).

The rising concern about COVID-19 pandemic has led universities across the world to either postponed or canceled all campus activities as measures to prevent and protect students and staff members from getting infected. Several countries have announced the closure of gyms, museums movie theaters, swimming pools, and places with large gatherings, inclusive of educational institutions, to fight this invisible enemy (Sahu, 2020). The lockdown of institutions not only affects students' internal assessments but also the academic calendar which becomes a source of worry for most students. Similar actions are observed around the world depending on the duration of the lockdown. The study of this year's university graduates may be severely affected by the COVID-19 pandemic. Students across the globe have experienced major teaching and learning disruptions in the final part of the semester which serve as the end of studies for those in the final year. The students have also experienced major disruptions in their assessments, and are likely to graduate at the beginning of a major global recession due to the pandemic. For instance, postgraduate students might entertain fear of not getting desired job considering specialization and competition following the negative repercussion of the lockdown. Pakpour and Griffiths (2020) stated that many people have started to be worried about their jobs and not just in lower-income and middle-income countries. The thought is that poor market conditions at labour market entry cause new entrants to accept lower paid jobs, and that this has permanent effects for the careers of some. Oreopoulos et al (2012) show that graduates from programmes with high predicted earnings can compensate for their poor starting point through both within- and across-firm earnings gains, but graduates from other programmes have been found to experience permanent earnings losses from graduating during recession.

Generally, this paper analysed responses to questions pertaining to the experience of international postgraduate students as a result of the disruptions by the COVID-19 pandemic. Specifically, the study focuses on the effects of physical distancing and self-quarantine on 
these students and the ways of adjustment to cope with the situation. These are measure put in place by the governments to mitigate the impacts of the COVID-19 pandemic which however has effect on students who observe them. All the results were organized and gathered into a descriptive form to analyse the experiences and coping strategies postgraduate students used during the self-quarantine period.

\section{Methods}

This study adopted a qualitative design using interview protocol. The open ended questions were designed to find out the respondents' experience of COVID-19 and the level of impact of self-quarantine and physical distancing and their expectation after the pandemic. The interview protocol was administered through email and social media (WhatsApp call for consent). The period of 10 days (April $18-28,2020$ ) was given for the protocol to be returned. An online interview protocol was sent to students located at Desa IImu and Unisquare in Kota Samarahan and Idaman in Gombak. The study was carried out through the qualitative method for the collection of relevant data through interview protocol. This method is appropriate because it suits the current condition and also provides complete information of postgraduate student's experiences of self-quarantine under the period of the control order in the country. For this purpose, a structured interview protocol had been constructed to elicit the relevant information.

\section{Data Collection}

The study used the survey method based on online interview protocol with international postgraduate students observing physical distancing and self-quarantine Kota Samarahan and Gombak respectively in Malaysia. The researchers reviewed and extract phrases and sentences which were related to the COVID-19. More than 30 students were contacted through WhatsApp calls and text messages to seek their consent and to take part in the research. The researchers made use of 15 received protocol as they were found suitable to be included in the study. The qualitative data were manually coded and themes generated. The themes generated were to discover the hidden meanings in the phrases in the contexts of the control order and self-quarantine.

\section{Findings}

This research sought data from postgraduate students who were contacted to hear their experience of the disease and the control measures put in place to curb its spread. These data generated issues regarding experiences and ways of coping with the situation during the period of self-quarantine and physical distancing. The themes generated were regrouped into three main themes such as shared psychological experiences, optimism from confusion and students coping strategies. The themes were discussed in the subsequent paragraphs.

\section{Shared Psychological Experiences}

The need for effective and efficient Wi-Fi became crucial for students to connect to their parents, love ones and also provide avenue to download articles to continue with their research. Before lecturers and students can engage in more research activities, the internet connection needs to be stable for possible progress. It is certain that, students quarantined are in position to generate the best ideas from the articles read if not disturbed mentally. As indicated by one respondent, it is possible for lecturers to upload new slides for undergraduates to read and prepare for the resumption of the current semester. But same 
cannot be said about us whose mode of study is by research as the need to meet supervisors and colleagues for discussion is crucial since the effectiveness of face-to-face cannot be compared with online or call. The thought of respondent was shared:

... the lecturer can upload all the slides and reading materials on eleaps so that ... who wants to study or prepare for the next ... own revision I wish there was no internet problem ... if the movement order is expend because not everyone has a strong and stable internet connection at home and to have own stable one it will cost money (Juaim)

The Covid19 situation is very critical and may be seen the biggest pandemic of human era. It is continuing and very possible to cross several days or months to come without vaccine insight become worrisome. Students stick to the advice to be very careful and continue to practice the control measures in order not to cause further mass destruction. The closing down of educational institutions and subsequent imposition of the control order brings about stressful situation for postgraduate students. The respondents have issues with extension of time of study as it will affect the leave granted by their sponsors in they are not able to finish within the sponsorship period.

I am studying in a PhD program funded by my country govt. with the condition of finishing it within 3.5 years. But due to MOC for Covid-19 pandemic I am afraid unable to continue my study and finish in time (Azraq)

Some felt that self-quarantine could also lead to unpleasant consequences such as face a higher chance to be less sane when raise concern that extroverts need the outside world in order for them to function and think rationally. By implication, this could lead to extreme unproductivity hence frustrated as boredom strikes. It is obvious that respondents reported experience of stress due to the restricted movement for a long time than expected. There was also complains of restlessness and inability to eat properly which may impact negatively on individual's health especially international students who are not able to return home. It is common knowledge that physical distancing and self-quarantine may cause anxiety and stress for those who are unable to do the usual routines like going to consult supervisors or engage in academic discussion with colleagues.

so I am in great ... treat to my sponsorship to finish my study within stipulated time lock down is home so no scope for refreshment to remove mental stress which is very difficult to sustain (Uyamah)

The outbreak of COVID-19 and self-quarantine may cause the students' mental reactions like tension, anxiety, and fear leading to stressful situation. In sharing their experience on selfquarantine, respondents report of mental disruptions as a result of overthinking about study and family leading to frustration. The researcher learnt that the frustration was also due to lack direct contact as they have less people to interact with face-to-face. This respondent said: Apart from that, my brain will not function as usual postgraduate needs guidance ... I feel stress and physically weak most of the time I tried to be more active but end up nothing but maybe try to sleep if I can ... besides that I feel empty because less people ... which I stuck inside far away from home (Arimiyam)

Similarly, Labram said:

it is a matter of too much thinking long research process the virus the quarantine to about which I don't want because of wasting my time patience and resources feel too much boring (Labram)

The COVID 19 pandemic has impacted negatively on the social and economic lives of students. Such situations lead to uneasy feeling especially for postgraduates whose studies are mostly by research they seem not be progressing. The mode of study requires meeting of supervisors 
very often but the restriction order made it impossible making life so miserable. This affects their interaction and without which no progress can be made putting much burden on the social life of general public and particularly students.

as a result of COVID 19 presently, I cannot go on visits supervisor like before I required as much to isolate myself from everyone close friends and relatives not stay close my supervisor will not want to see me offices lock to avoid spreading or contacting the virus (Ayyu)

The pandemic has created the need to completely restrict general public from meetings and other social gatherings like church meetings, parties and social ceremonies (that do not hold) which spice up lives. Economically, the complain of lack of funds to make purchases for certain necessaries are no longer available due to the restriction or order placed on movement making it difficult to receive money from students' home country. There are some selected services and goods which are not considered as essential the impact of which extends psychologically too.

I am not able to move around or to town where I can receive ... cannot also embark on visits like before I am not able to eat what I really want I am literally short of cash I mean I am out of cash (Kenisya)

One may be tempted to say self-quarantine allow people to have rest, present a sort of relative peace, public safety and reasonable safety on one's life and property. Nonetheless, the repercussion of self-quarantine and physical distancing may include boredom, financial loss, inadequate supplies, dissatisfaction, confusion, anger and internal conflict among others.

As much as the control order is good for all and it is targeted at public safety I do not feel good about the restriction and self-quarantine I want to be allowed to move freely (Zibtani)

They also get depressed being quarantined for too long and not living their normal lifestyle. Some of the respondents used depression in the loose sense probably to describe stress. One respondent complained of depression as a result of loneliness especially staying in a rented house and lives far from family. This suggests that the less active individual is the likely to be bored and easy to be stressful. One respondent expressed that:

self-quarantining makes me restless, unusual thoughts and mixed feeling often breakdown as one ... is impossible ... to isolate oneself long enough from social interaction (Dayyan)

They hope the quarantine will not be long otherwise the effect, most of them think, could be unbearable. In sharing, Izzalam said:

you tend to be vulnerable when staying alone in ... without any family living with you in living alone one their homes facing panic attacks alone or the feeling of loneliness if the MCO will be too long, the side effects we humans need to interact with one another being too long inside the house make oneself feel trapped.

\section{Students Coping Strategies}

The experience of fear of the pandemic is obvious considering what individuals go through in isolation especially when one is not able to do what you are supposed to be doing. As international students, it is important to consider what it is like for those with fear of missing out in academic programme or missing out colleagues who cannot be reached due to physical distancing or the family and loved ones far back home. To withstand the above frustrations and challenges, most respondents resort to their beliefs and viewed the current situation as destined. 
accepting the practical facts destiny is destined I do what I can do I don't think and try to think be try my ability do the right things according to the guidelines of Islam for Muslims and for non-Muslims I think according to the guidelines of humanity or what they belief (Ayyu)

Some also developed positive minds instead of thinking about the bad side (the spread and number of deaths) of the pandemic.

despite these I managed to survive well during this control order period and rarely think of the negatives side of it by staying optimistic about the whole situations many recoveries than deaths (Kaaky)

As much as search for research materials is essential, respondents were also engaged in reading any material online to broaden their knowledge or issues outside their specialization or areas of research. Quite apart, they explained of spending time watching and reading news about the Covid-19 from within and their home countries as well. In extending horizon of knowledge, online short courses also served as source of relief as some respondents got engaged. One respondent revealed that:

I try to ration my meal, I took up online courses, I always make myself happy by reading up news and stories from the internet I listen to music, read books, and get on social media chats and videos with friends and family (Juaim)

In self-quarantine and isolated from the public, the social media played crucial role as most of them were engaged in watching movies on Youtube, life-chat or online study just to occupy the idle mind, Dasyam shared that:

I have been peaceful, at ease I watch documentary ... prayerful and calm on the issue and challenges of self-quarantine because I know it is not anyone's fault the control order is for public good (Kenisya)

A respondent observed that:

this pandemic can waste a lot of time by ... watching videos online and ... it makes you feel a little bit okay but still lonely as you need someone to talk to, no matter how even introvert you are being lock even in your own house for a quite some time will make you less productive and unhealthy which you will just be inactive anyway videos keep bad thinking away (Gastro)

The mindset of the individual also came to play as some respondent see reasons to stay calm and with positive mind instead of thinking about the bad side like the spread of the virus and number of deaths. With that expressed faith in self-quarantine and wish the general public could abide by the instruction and control measures put in place for the good of all. To bear with the situation, Haizilad said:

myself I'm calm, positive thinking and everyone need to be calm and ... especially, at this challenging time we ... endeavour to observe the rules of government and quarantine ourselves. The idea is for the good of us all.

Similarly, Labram said:

I try to occupy myself with positive things ... studying, movies, music ... by accepting of the situation

Uyamah occupied the mind with past happy moments and reading material online.

it is better to do self-reflection ... spend time alone and think of the things that makes me happy and a better person it is a good time to learn to value myself it is wise to be grateful ... next one can read articles online or books (Uyamah)

\section{Optimism from Confusion}

Every misfortune has a good side, so can be said about the Covid-19. The positives from the self-quarantine and physical distancing are that governments and authorities are able to put 
control and protective measure in place. The general public is protected from getting infected with the Covid-19 as well as contains its spread from one person to another. Thus, spreading of virus is slowed as people are quarantined. As such the students could prevent themselves from being infected with the Covid-19 when follow the guidelines and observer selfquarantine. The respondent did not hesitate to state the beneficial side of the self-quarantine under observation. They posit that it helped them to be more concern about their health and cleanliness thus referring to the regular washing and sanitizing of hands, wearing mask and eating nutritious foods to improve the immune system. Apart from that, the 'quality' time family members now have to reflect and set their life goals is noteworthy. When asked about the general Covid-19 experience, Alizato said:

it ... serves as time for family bonding and to be more appreciative of the blessings we took for granted ... brings about self-improvement those who have stable mind can learn new skills like like example painting or cooking which strengthen the bond with the family members since everyone is stacked up.

Self-quarantine is a great control measure to break the chains of infections of the disease. It also brings about innovative ways of doing thing as the student are getting advance in elearning and run online platforms as well as working on assignments from home and able to have quality group discussions and time with family members. Students are able to work on their assignments efficiently as they have ample time to focus on their tasks.

I am able to get enough sleeps even though with unpleasant dreams probably from my daily thoughts it is good for doing self-reflection, and ... oneself by doing exercise, yoga, trying new recipes new things I mean learn try new things.

\section{Discussion}

The spread of the virus led countries to simultaneously apply social distance and physical distance which did not only curtail the growth of COVID 19 but also inhibited educational activities throughout the world. The temporary closure of educational institutions by most governments around the world due the COVID-19 pandemic had impact on international students. Studies show that the outbreak of COVID-19 may cause tension, anxiety, and fear leading to psychological disorders such as acute stress disorder, post-traumatic stress disorder, depression and even suicide especially among students (Zhong et al., 2020). The measures put in place governments to support universities in their efforts to reduce the direct impact of closures of institutions are specifically meant for the more vulnerable and disadvantaged local students. The international students only survive on remittance from home countries which is not easy for them to receive as money transfer agents are not included in those identified as essential services under the movement order. Besides, postgraduates might not benefit much from the directives that all educational institutions conduct online/distance learning and/or advice students to learn from home. The difficulty for postgraduates is that they need to meet with their supervisors for proper academic discussion which might not be effective if it were to be done online or through phone calls as provided undergraduates. It is explained that anxiety disorders are more likely to occur and worsen in the absence of interpersonal communication (Xiao, 2020; Kmietowicz et al., 2020; Cao et al., 2020). The continuing spread of the disease, strict isolation measures and not knowing when universities will bounce back to life throughout the country also affect the mental health of these students. Most of these students experienced anxiety living without their parents, fear for the stability of family income as their only source of sustenance during the COVID-19 outbreak. In corroboration, Cao et al. (2020) found students' anxiety was 
associated with their place of residence, source of parental income, whether living with parents and whether a relative was infected with COVID-19. As much as they think about their own safety, same is said about that of the loved ones at their home countries. The students' anxiety, frustration and boredom might have been caused by the increasing distances between themselves and loved ones resulting from the quarantine (Cao et al., 2020). They are worried of having relatives or parents getting infected with COVID-19 thus constitute an independent risk factor for anxiety and frustration.

As the disease continue to spread across boarder, governments, health authorities and scientist teamed up in countries to determine and introduce measure like physical distancing, quarantine among others to slow the spread and transmission of the disease. For fear of the spread and transmission, semesters of schools and universities discouraged face-to-face interaction initially but later were truncated and asked to adhere to physical distancing as well as self-quarantine. Mei et al. (2011) suggested that public health emergencies can affect students psychologically and may be expressed as anxiety, fear, and worry among others. The laws and policies restricting the movement of people thus mandate students to leave home only for essential goods and services as Malaysia declared complete quarantine and only allow movements for food or for health care. As opined, the threat of contracting COVID-19 makes it quite prudent for people to be sensitive to the disease and take precautions like social distancing (Casale, \& Flett, 2020). Life must go on, so students in particular and employees who could work from home were doing so remotely during the self-quarantine and physical distancing. Studies show that emotional adjustment reactions like fear of contagion impact of prolonged quarantine, the death of love ones, or increased social adversity as a consequence of geopolitical instability to civil society associated with the economic crisis due to the disease (Zhou, 2020; Brooks et al., 2020; Xiao, 2020; Wang et al., 2020).

The experience of Covid-19 and its consequences on students' academic lives are no exception during this trying and transformative period. There have been reports on the psychological impact of the pandemic on the general public to include student, patients, medical staff, children and older adults (Chen et al., 2020; Yang et al., 2020; Li et al., 2020). The speed at which the disease spread across the globe is alarming considering the number of people infected and the expected long-term consequences that it may put on student's education progression, social relations, delay in joining the work force among others. In trying times like this, YouTube, WhatsApp and other social media platforms served as a source of entertainment and communication to ease the burden of the students observing the control order. As such, respondents were quick to report that the Covid-19 had provided opportunities for self-reflection and how the disease could affect their academic activities and social life. Despite the possible emotional distress and unbearable life students might have experienced, the student believed that the confinement by their institutions was by and large for their wellbeing and safety. Apart from the thought of getting infected or a relative getting infected by Covid-19 and lose of loved ones, the feel of uncertainty was clear in the students' narratives. Studies showed that the anxiety, fear and sadness exhibited by international students about COVID-19 might be related its effects on their studies and future employment opportunities (Wang et al., 2020; Cornine et al., 2020). In case the selfquarantine continuous, postgraduate supervision will also have to be conducted on-line to ensure students make progress in research activities to avoid frustration and possible 
stressful situation. Most of the postgraduate students live in rented small apartment and may need some sort of adjustment in schedules and work plan.

The respondents found it imperative to stay positive in order to contain the fear and stress of the Covid-19. Even though, Cao et al. (2020) the hoax news circulated about the Corona virus on social media make students uneasy and sad. In an attempt to put the students' coronavirus experience in perspective, previous studies show that individuals are more prone to anxiety, repetitive worry and psychological stress such that they lack sense of self-efficacy to control and overcome current uncontrollable situations and anticipated future circumstances (Flett, \& Blankstein, 1994 cited in Casale, \& Flett, 2020). With positive thoughts, they are able to spend their time wisely during the period but due to frustration and boredom they were unable to concentrate on anything. Jiang (2020) objective measures like effective infection control, personal protective measures, clear institutional policies and protocols may help to reduce stress. The students are able to survive the consequence of the pandemic with responsible attitude and behavior towards observance of the control order. Pakpour (2020) argues that knowing the level of fear about COVID-19 among individuals for that matter students with different backgrounds like gender, age, education, ethnicity, makes it easy to know whether education and prevention programs are necessary and the groups that need it. Such information could be used to devise targeted education programs to help overcome fear of future pandemic among students and to engage in preventative behaviors in future.

\section{Conclusion}

The thought of the international students is that the authority should allow those who have self-quarantined enough to be sent back to their homes in restricted manner and in suitable amount of batches to avoid any new clusters from arising. The COVID-19 pandemic is first and foremost a health crisis and security dilemma. Many countries have directly without hesitation decided to close schools, colleges and universities and all educational related centers are still not functioning normally. The crisis crystallizes the dilemma educational and even economic policymakers are dealing with between closing schools, colleges and university aiming to reduce contact and save lives or, keep them open means allowing workers to work and maintaining the educational activities stable. The severe short-term of approximately three months or four in some places disruption up to now is felt by many communities around the globe. Home schooling and tuitions are not only shocking to most parents, but also students' social life and learning as higher percentage of teaching and learning is moving online. The full migration to online teaching and learning is untested to determine whether it would succeed or fail still dilemma and the victims are likely to be the entire world. Covid-19 leads to adjustments that result in new approaches, unexpected adaptations and a much wider field of options. The idea is that students continue their education at home, in the hope of not missing out too much. The closure of schools, colleges and universities due to COVID-19 not only interruption for students around the world but also coincides with a key assessment period where many exams had to be postponed or cancelled. The majority of universities and colleges are replacing traditional exams with online assessment. 


\section{References}

Brooks, S. K., Webster, R. K., Smith, L. E., Woodland, L., Wessely, S., Greenberg, N., \& Rubin, G. J. (2020). The psychological impact of quarantine and how to reduce it: rapid review of the evidence. The lancet, 395(10227), 912-920.

Cao, W., Fang, Z., Hou, G., Han, M., Xu, X., and Dong, J. (2020). "The psychological impact of the COVID-19 epidemic on college students in China," Psychiatry Res., vol. 287, no. March, p. 112934,

Casale, S., \& Flett, G. L. (2020). Interpersonally-based fears during the COVID-19 pandemic: reflections on the fear of missing out and the fear of not mattering constructs. Clinical Neuropsychiatry, 17(2).

Chen, Q., Liang, M., Li, Y., Guo, J., Fei, D., Wang, L., He, L., Sheng, C., Cai, Y., Li, X., Wang, J., Zhang, Z., (2020). Mental health care for medical staff in China during the COVID-19 outbreak. The Lancet Psychiatry.

Cornine, A. (2020). Reducing nursing student anxiety in the clinical setting: An integrative review. Nursing education perspectives, 41(4), 229-234.

Jiang, Y. (2020). Psychological Impact and Coping Strategies of Frontline Medical Staff in Hunan between January and March 2020 during the Outbreak of Coronavirus Disease 2019 (COVID 19) in Hubei, China. Med Sci Monit, 26, 924171.

Joob, B. (2020). Self-quarantine for COVID-19 among returning illegal Thai workers; observation. Journal of Injury and Inflammation, 5.

Mei, S. L., Yu, J. X., He, B. W., \& Li, J. Y. (2011). Psychological investigation of university students in a university in Jilin province. Med Soc (Berkeley), 24(05), 84-86.

Mohammed, A. A., Uddin, M. S., \& Saidi, A. M. (2020). Covid-19 And Movement Control Order: Stress and Coping Strategies of Students Observing Self-Quarantine. International Journal of Academic Research in Business and Social Sciences, 10(5), 788-802.

Pakpour, A. H., \& Griffiths, M. D. (2020). The fear of COVID-19 and its role in preventive behaviors. Journal of Concurrent Disorders.

Sahu, P. (2020). Closure of universities due to coronavirus disease 2019 (COVID-19): Impact on education and mental health of students and academic staff. Cureus, 2019 (4), 4-9.

Wang, C., Horby, P. W., Hayden, F. G., \& Gao, G. F. (2020). A novel coronavirus outbreak of global health concern. The lancet, 395(10223), 470-473.

Xiao, C. (2020). A Novel Approach of Consultation on 2019 Novel Coronavirus (COVID-19)Related Psychological and Mental Problems: Structured Letter Therapy. Psychiatry Investigation, 17(2), 175-176.

Xiao, C. (2020). A novel approach of consultation on 2019 novel coronavirus (COVID-19)related psychological and mental problems: structured letter therapy. Psychiatry investigation, 17(2), 175.

Yang, Y., Li, W., Zhang, Q., Zhang, L., Cheung, T., \& Xiang, Y. T. (2020). Mental health services for older adults in China during the COVID-19 outbreak. The Lancet Psychiatry, 7(4), e19.

Zhong, X., Liu, X., \& Liu, J. (2020). Psychological state of college students during COVID-19 epidemic. Available at SSRN 3552814.

Zhou, X. (2020). Psychological crisis interventions in Sichuan Province during the 2019 novel coronavirus outbreak. Psychiatry Research, 286(February), 112895. 